\title{
Investigating the Use of Knowledge Management Tools within the Saudi Arabian Public Sector Organisations
}

\author{
Suresh Renukappa* \\ Faculty of Science and Engineering, \\ University of Wolverhampton, \\ Wolverhampton WV1 1LY, UK \\ Email: suresh.renukappa@wlv.ac.uk \\ *Corresponding author \\ Khaled Algahtani \\ Faculty of Science and Engineering, \\ University of Wolverhampton, \\ Wolverhampton WV1 1LY, UK \\ Email: k.m.a2@wlv.ac.uk

\section{Saeed Al Nabt} \\ Faculty of Science and Engineering, \\ University of Wolverhampton, \\ Wolverhampton WV1 1LY, UK \\ Email: S.AlNabt@wlv.ac.uk

\section{Subashini Suresh} \\ Faculty of Science and Engineering, \\ University of Wolverhampton, \\ Wolverhampton WV1 1LY, UK \\ Email: S.Subashini@wlv.ac.uk

\section{Hanouf Alosaimi} \\ Faculty of Science and Engineering, \\ University of Wolverhampton, \\ Wolverhampton WV1 1LY, UK \\ Email: H.Alosaimi@wlv.ac.uk
}

\begin{abstract}
Recent technological developments have made a significant and positive impact on the ability and desire to manage knowledge. Therefore, the aim of this paper is to explore the usage of key knowledge management (KM) techniques and technologies for dealing with change initiatives in the KSA public sector organisations. A web based, online questionnaire survey method was employed to collect data. The survey revealed that conventional, simple and cost effective KM techniques and technologies such as telephone, internet, face-to-face meetings, WhatsApp, and formal education and training programmes are extensively used. Whereas modern KM techniques and technologies such as Viber, FaceTime, LinkdIn, Informal networks, and knowledge maps are less used. The paper concludes that to gain competitive advantage, it is necessary for KSA public sector decision makers to recognise and use a blend of ICT and nonICT based KM techniques and technologies.
\end{abstract}


Keywords: Knowledge Management, Kingdom of Saudi Arabia, Tools, Techniques and Technologies

Biographical notes: Suresh Renukappa currently serves as a Senior Lecturer in the Faculty of Science and Engineering at the University of Wolverhampton. He holds a PhD in managing change and knowledge associated with sustainability initiatives for improved competitiveness. He has over 20 years of research, consultancy, project management and teaching experience in a wide range of business and management areas across industrial sectors in both developed and emerging economies. His research interests cover, but not limited to, sustainability strategies for competitive advantage; carbon reduction strategies; corporate social responsibility; smart cities development; leading change towards sustainability; knowledge management; public private partnerships; cloud computing; infrastructure asset management; and sustainable infrastructure investment and development. He has successfully executed more than 30 large projects and authored over 80 papers which have been published in journals, book chapters and conference proceedings.

Khaled Algahtani is a $\mathrm{PhD}$ researcher in the Faculty of Science and Engineering at the University of Wolverhampton. His research examines the current level of understanding and implementation of Knowledge Management Practices' in Saudi Arabian Public Sector Organisations for sustainable competitive advantage. He holds Master in Administration Management from the Wolverhampton Business School, UK. Khaled graduated from King Saud University of the Kingdom of Saudi Arabia with a Bachelor of Science in Business Administration. He has over12 years of experience in private and public sectors in the Kingdom of Saudi Arabia. He received scholarship from his current employer the Ministry of Justice in the Kingdom of Saudi Arabia to do his post-graduate and doctoral degrees. Mr Algahtani has published three international papers. His recent publication include a book chapter in Springer Business and Economics book. His research interests include: knowledge management in public sector organizations, leading change initiatives, training and education, and organisational development.

Saeed $\mathrm{Al} \mathrm{Nabt} \mathrm{is} \mathrm{a} \mathrm{PhD}$ researcher in the Faculty of Sience and Engineering at the University of Wolverhampton. His research investigates the role of Leadership for successful implementation of Knowledge Management related change initiatives within the Saudi Arabia public sector organisations. He holds Master in Business Administration from the Wolverhampton Business School, UK. Saeed graduated from King Saud University, the Kingdom of Saudi Arabia with a Bachelor of Arts. He has over 12 years management experience in private and public sectors in the Kingdom of Saudi Arabia. He received scholarship from his current employer the General Authority of Zakat and Income Tax in the Kingdom of Saudi Arabia to do his post-graduate and doctoral studies. Mr. Al Nabt has published three international research papers. His recent publication includes a book Chapter in Springer Proceedings in Business and Economics. His research interests include: Strategic Leadership, Knowledge Management, Change Management, and Competitiveness.

Subashini Suresh has over 19 years of experience in research, teaching and practice in the area of Project Management and has worked in the area of Architecture, Engineering and Construction (AEC) sector in UK, USA, UAE, Nigeria, Ghana, Italy, Netherlands and India. Currently, she is 
a Reader of Construction Project Management at the School of Architecture and Built Environment, University of Wolverhampton. She holds a PhD in knowledge management. She received Rewarding Excellence Award for Innovation in Teaching and also for Blended Learning Tutor. She has published over 150 academic publications, which include 27 journal papers, 95 conference papers, four articles, eight book chapters, 15 reports and three books. Her key areas of interest are as follows: construction project management, knowledge management, building information modelling, health and safety, sustainability/green construction, emerging technologies, quality management, leadership in change management initiatives, organisational competitiveness, business process improvement, lean construction, risk management, and Six Sigma leadership.

Hanouf Alosaimi is a PhD researcher in the Faculty of Science and Engineering at the University of Wolverhampton. Her research investigates the current level of understanding and implementation of knowledge management practices in the Kingdom of Saudi Arabia construction industry for competitive advantage. She holds Master of Business in Human Resources Management from the Wolverhampton Business School, UK. Hanouf graduated from King Saud University of Saudi Arabia with a Bachelor of Social Work. She received scholarship from Saudi Arabian Cultural Bureau to do her MBA and PhD degrees. She has published two conference papers in the area of knowledge management. Her research interests include: human resources management, knowledge management, women in Saudi Arabian construction industry and competitiveness.

\subsection{Introduction}

The unfortunate convergence of increasing oil supply and weakening global demand has created an oversupplied market and caused a 55\% decline in international crude oil prices (EY, 2017).

The fall in crude prices has prompted the biggest leadership, economic and policy shake-up in the history of Kingdom of Saudi Arabia (KSA). The KSA Government has cut the public sector bonuses and benefits for the first time since the collapse in oil prices, in a move that underlines the depth of the fiscal crisis facing the kingdom. Since 2014, oil prices have fallen by more than fifty percent and this loss of revenue has caused the Saudi Government to draw down its foreign currency reserves, return to the capital markets to issue bonds, raise taxes, reduce spending and greatly reduce subsidies offered on energy. Collectively, these actions have had an adverse effect on the domestic economy, causing GDP growth to slow, share prices to fall, pressure to mount on the currency and inflation to rise (Fattouh and Sen, 2016). The Government aims to reduce 
fiscal deficit by improving state efficiency, reducing costs, as well as its state subsidies. Consequently, the KSA Government has announced an ambitious new strategy: Vision 2030 (Fattouh and Sen, 2016). The National Transformation Programme (NTP) is a detailed strategy to implement the broader Saudi’s Vision 2030.

The NTP aims to reduce unemployment from $11.7 \%$ to $9 \%$ by 2020 and $7 \%$ over the following decade. Therefore, the KSA Government has the ambitious target of creating 450,000 private sector jobs by 2020 through the expansion of non-oil sectors. But at the same time it plans to decrease the civil service by $20 \%$, as part of its aim of reducing the dominant role of the state. This is definitely a big challenge because Saudis have grown accustomed to working in the more 'relaxed' public sector environment. Furthermore, the demographic shift in the work place, whereby a large percentage of the working population will retire in the coming five to ten years. This has created unrest among the public sector organisations when their best employees depart. In addition to this, the climate change, the knowledge economy, and commitment to the principle of sustainability, pose profound strategic challenges for the public sector organisations in the KSA and beyond. Therefore, to address these issues and challenges, the KSA public sector organisations have to modify and/or amend many strategic, structural, financial, and operational changes.

According to Drucker (1995) knowledge has become the key economic resource and the dominant, perhaps even the only, source of competitive advantage. It has been observed that at the heart of an organisation's strategy process is a force, which has been termed as the "knowledge force', which is powered by the knowledge workers. Today, public sector organisations are also known as knowledge-based organisations and knowledge is as critical a resource to public sector organisations as it is to private sector firms (Siong et al., 2011). 
Knowledge is one of the building blocks for an organisation's success and acts as a survival strategy in this knowledge era (Witherspoon et al., 2013). Therefore, knowledge resource resides in employees' minds and organisations have to utilise this valuable resource for their competitive advantage (Lin and Hwang, 2014).

Boyne (2002) noted that there are significant approaches that redefine the processes of management and its pursuit in public organisations and values like the expression method and performance evaluation obtained by the public mangers. Todericiu and Stanit (2016) noted that knowledge management $(\mathrm{KM})$ one of the process of the new management techniques. It is the process of the organisational knowledge to give value to the organisations and it plays an important role in achieving sustainable competitive advantage (ALSarhani, 2016). According to Easterby and Lyles (2011) organisations that implement KM effectively see their performance positively improve. KM is used for solving problems within the organisations, even when we are dealing with a service that represents an innovation in the public sector. KM helps organisations to identify, document and store as well as re-distributing experiences. Furthermore, it facilitates the relationships with the beneficiaries, the partners and the suppliers of the public sector organisations (Bhatt, 2001; Alsereihy et al., 2012).

In addition, organisations categorise $\mathrm{KM}$ initiatives as part of their long-term strategy so that their organisational knowledge can be retained. Due to an increase in employee turnover, it has become important for organisations in KSA operating in either the public or private sector to consider different methods for capturing knowledge which have been gained by employees during their course of work (ALSarhani, 2016). KSA organisations have been implementing KM solutions but they face a number of issues and challenges in their implementation such as 
complying with Saudi government regulations and rules (ALSarhani, 2013). Furthermore, the work environment in Saudi organisations contains a number of restrictions that also limit the implementation of KM practices (ALSarhani, 2013). However, it has been observed that organisations that have adopted KM techniques have developed their productivity through various methods that include reducing turnaround time (ALSarhani, 2016). However, the implementation of KM requires the availability of a range of elements, such as the appropriate organisational structure that leads to independence in decision making and organisational environment to gain access to knowledge (Salwa, 2015). This environment requires some factors such as organisational structures for KM, leadership, organisational culture, and information and communication technology (ICT) infrastructure (Salwa, 2015). For instance, a culture of knowledge sharing has to be formed to transform the behaviours and attitudes of individuals working in the organisation as well as to cut down barriers (Bolisani and Handzic, 2014). Therefore, it is necessary to increase awareness of the advantages of KM. Staff and managers are supposed to be well informed about the changes and benefits that KM can offer them as well as their organisation. Although they feel and acknowledge the power of knowledge, they have to believe in the power of sharing knowledge (Bolisani and Handzic, 2014).

Kim et al, (2014) noted that staff has to be formally rewarded and recognised, not just for knowledge sharing with others but also for their willingness to utilise the knowledge shared by others. Furthermore, it is very important for organisations to create and foster communities of practice (COPs). COPs are organisational centres of knowledge in which individual groups having similar job-related duties but do not participate in an officially established work team generating, disseminating and practising knowledge (Bi and Jiang, 2012). COPs can have a wider significance than simply sharing implied knowledge. These can be productive in the 
activities of the public sector, either on a specific or generic basis. Organisations need to foster COPs by ensuring the availability of resources and also through permitting members the chance to participate in order to develop and sustain COPs (Bi and Jiang, 2012).

After a decade of sustained oil-based growth, KSA is at a transition towards knowledge based economy. According to Al-Kibsi et al. (2015), there has been an increased focus in KSA on shifting away from an oil-based to a knowledge-based economy. However, the efforts that have been adopted to move towards knowledge economy are not yet sufficient developed and implemented KM technology and techniques. Today, achieving that goal has become essential. To address change challenges, knowledge is increasingly accessed and shared across different functional departments and professionals. This knowledge interdependence creates new management challenges resulting from the risks and difficulties of knowledge transactions across boundaries. Providing access to key tacit and explicit knowledge to decision makers during potential changes seems to be critical for effective decision-making. Recent technological developments have made a significant and positive impact on the ability and desire to manage knowledge. Even though many authors argue that access to, and, effective use of knowledge is a critical element in shaping and managing change in transitions there is little empirical research on the key KM techniques and technologies that are used within the KSA public sector organisations. Therefore, the aim of this paper is to explore the usage of key KM techniques and technologies within the KSA public sector organisations.

\subsection{Knowledge management techniques and technologies}

Tools are usually required to facilitate KM. Just as it can prove difficult to arrive at a single definition of $\mathrm{KM}$, firm definitions of $\mathrm{KM}$ tools can also prove elusive owing to the lack of 
consensus regarding what constitutes a KM tool. For instance, Egbu, et al., (2005) noted that non-IT tools are termed as KM techniques and the IT tools termed as KM technologies. Pfeffer et al, (2013) assert that KM tools can be information technology-based but are not necessarily so. However, Massingham (2014) noted that the term 'KM technologies' refers to information technology-based tools and 'KM techniques' refers to non-information technology-based tools. KM technologies involve an information technology infrastructure and require the input of explicit knowledge. In contrast, KM techniques are people-based and require the input of tacit knowledge that can be derived from personal interaction such as brainstorming. Ruggles (1998) noted that not all tools are computer based but much emphasis is placed on the electronic tools due to their dynamic capabilities, quick evolution, and organisational impacts. He does not differentiate the term KM techniques and technologies whereas he terms it as KM tools.

Massingham (2014) asserts that KM tools are able to amass data from various sources and classify, integrate and codify these data. In addition, Massingham (2014) suggests that these tools make it possible to retrieve and reveal knowledge and can also be employed in order to disseminate knowledge among staff. Pfeffer et al. (2013) state that KM tools are technologies that facilitate KM sub-processes such as codification and knowledge transfer. Alternatively, Massingham (2014) suggests that the terms 'KM tools' and 'KM techniques' are interchangeable and believe that KM techniques are simply the means through which knowledge is managed using tools. The lack of consensus in the empirical literature therefore poses a question regarding what the practical differences and similarities are between tools, technologies and techniques.

Davenport and Prusak (1998) assert that KM tools are more than information technology it is about the people who add value by transforming static data into meaningful information and knowledge by mixing it with their own experience and interpretations. Therefore, Davenport and 
Prusak (1998) acknowledge that KM techniques and technologies are mutually dependent. There are various terminologies that have been used to distinguish between information technology tools and non-information technology tools in the empirical literature. For instance, Vacik et al. (2013) use the terms 'organic' and 'mechanistic;' Massingham (2014) opts for 'soft' and 'hard;' while Vacik et al. (2013) refer to 'personalisation' and 'codification' tools. In this study, KM techniques and technologies are not differentiated. This is because in most scenarios techniques and technologies are interdependent and support KM activities such as knowledge mapping, knowledge capturing and knowledge sharing. Table 1 summarises the core differences between KM technologies and techniques.

Table1: Key differences between KM technologies and techniques

\begin{tabular}{|c|l|}
\hline KM Technologies & \multicolumn{1}{|c|}{ KM Techniques } \\
\hline - Based on explicit knowledge & - Grounded on tacit \\
- Involves information & knowledge \\
technology infrastructure and & - People-based \\
know-how & - Easy to set up and maintain \\
- Can be difficult to set up and & - Relatively cheap to set up \\
maintain & and maintain \\
- Expensive to set up and \\
maintain
\end{tabular}

Source: Massingham (2014).

\subsection{Research methodology}

Research is defined as the process by which a person attempts to find an answer to a question or a solution to a problem through a systematic methodology with the aid of an evident fact (Leedy and Omrod, 2012). It is not only a set of skills but a way of thinking, by looking at a situation inquisitively, analytically and critically so as to gain an in-depth understanding of its relevance, 
rational, efficiency and effectiveness (Kumar, 2014). The systematic way of achieving the solution to a problem is through a research methodology (Rugg and Petre, 2007). According to Grix (2010) research methodology is a systematic approach that describes how a piece of research should be undertaken to achieve certain objectives through the use of research methods. These research methods are techniques or processes employed by researchers to conduct, collect and analyse data (Kinash, 2006). Therefore, it is imperative to first define the reason for conducting a research because the choice of a research method is inextricably linked to the research question asked and to the sources of data collected (Bryman and Bell, 2015). Research methods are techniques or processes employed by researchers to conduct, collect and analyse data (Kinash, 2006).

Given the relatively new and unexplored nature of the research problem at hand, a quantitative method was adopted to collect and analyse data. The philosophical underpinning of this is based on objectivist-positivist paradigms. Questionnaire survey instruments have many advantages in the data collection process. They provide a larger geographical coverage for the sample population than case studies or semi-structured interviews could provide (Bourque and Fielder, 1995) and are cost-effective, efficient, and permit anonymity. The latter helps ensure that individuals' responses reflect their true beliefs and feelings-especially important in research involving attitudes. Because the researcher is not conversing directly with participants, they are unlikely to influence respondent answers. The questionnaire survey also provides a uniform situation for data collection, because each person is presented with the exactly the same method of inquiry, in the same manner (Bryman and Bell, 2015). 
A web - based, online survey was used to collect data. This offers many advantages including low cost, speed, and ability to reach respondents globally (Punch, 2005). A robust questionnaire survey design is fundamental to obtaining reliable survey results and an appropriate response rate (Bryman and Bell, 2015). Questionnaire variables used in the study were derived from the literature review. The specific questions were written with focus on the response process, the utility of individual questions, and the overall structure and appeal of the questionnaire. The cover page introduced the research project and provided critical information such as a confidentiality statement and important notes for completing the questionnaire. The study included scaled items for opinion questions. The final page of the questionnaire provided an option for respondents to offer any further general comments relating to the area of research. Respondents were also able to request a summary of the survey findings to encourage a higher response rate. Fellows and Liu (2015) noted that Likert items are concerned with determining respondents' degrees of agreement or disagreement with a statement, usually on a 5-point or 7point scale. A general problem occurs in the application of opinions or attitude scales in questionnaire surveys: respondents tend toward the neutral position. That is, when asked to strongly agree or strongly disagree on a 5-point or 7-point scale, many respondents would prefer to choose "neither agree nor disagree." Analysts often exclude neutral responses from their analysis, thereby risking the exclusion of valid responses. The disadvantage of this among surveys is that it reduces the quantity and quality of remaining data. Therefore, a 4-point Likert item was used in the study to avoid this.

The sampling technique used was convenience sampling. According to Black (2010), in convenience sampling, elements for the sample are selected for the convenience of the researcher, hence the researcher typically chooses target respondents who are readily available, 
nearby, or perceived as willing to participate. This was decided upon because there is no comprehensive, standard e-mail database of Public Sector organisations within KSA. Therefore, sources such as the Institute of Public Administration (IPA), King Abdul Aziz City for Science and Technology (KACST), and a more general search of the Internet were used to identify cases for inclusion in the sample. However, according to Bajpai (2010), this method eliminates the chance factor in the sample selection process, and therefore suffers from non-randomness

Survey invitations were e-mailed to respondents requesting that they submit their views via an online survey hosted at https://survs.com/survey/ko8yrsk0sm. Overall, a total of 107fully completed and usable questionnaires were received. Saunders et al. (2009) argue that a minimum number (i.e., effective responses) for statistical analysis should be 30 responses. Therefore, 107 responses were deemed appropriate for a survey of this kind. Of the survey responses, 43 were from managers, and 64 were from directors. A relatively large percentage $(60 \%)$ of survey respondents therefore occupied directors' roles within their organisations. Based on designation and professional background, it is reasonable to infer that respondents held adequate KM expertise within Public Sector organisations within KSA, and all were of a maturity and sophistication to understand the questionnaire and its relationship to the research aims.

Statistical analyses were undertaken using the Statistical Package for Social Sciences (SPSS version 21). These included descriptive statistical analysis and the t-test to compare equality of mean responses between managers and directors. This test is appropriate for comparing the means of two large, independent samples; two independent samples of any size; two dependent samples; or a sample mean and a known mean (Weiers, 2011). Cronbach's $\alpha$ was calculated as a way of determining the internal consistency, or average correlation of items, in the questionnaire 
to gauge its reliability (Nunnaly, 1978). The Cronbach's $\alpha$ statistics were in the range of $0.81-$ 0.93. This implies a high degree of internal consistency in the responses to the individual measures, as $\alpha$ values above 0.7 are acceptable indicators in this respect (Nunnaly, 1978).

\subsection{Usage of KM techniques and technologies within the KSA public sector organisations}

Through the online survey, respondents were asked to indicate the usage of KM techniques and technologies on a 4-point Likert item: "Always used" (4), "Often used" (3), "Sometimes used" (2) and "Never used" (1). It is apparent from Table 2 that the five most widely used KM techniques and technologies are: telephone (3.32), internet (3.12), face-to-face meetings (2.86), WhatsApp (2.84), and formal education and training (2.81). Whereas, the five least used KM techniques and technologies are: Viber (1.71), FaceTime (1.84), LinkdIn (1.91), Informal networks (2.01), and knowledge maps (2.06).

The t-test for equality of means was carried out to investigate if there were any significant differences between 'directors' and 'managers' insights on the usage of KM techniques and technologies (at the 0.05 significance level) (refer Table 1). According to Black et al. (2010), in the t-test, a significant value $(\rho)$ below 0.05 indicates a high degree of difference of opinion between groups on that variable (in this case, between 'directors' and 'managers'). Results here show that all KM techniques and technologies, apart from internet, are not significant $(>0.05)$, and therefore, there are no significant statistical variations between the responses of the 'directors' and 'managers'. In this study, managers (with a mean value of 3.37) perceive that internet is being more widely used for managing knowledge than directors (with a mean value of 2.95). Sultan (2013) noted that internet is regarded as one of the most efficient tool and technology that has been helping organisations in KM. Alshahrani (2016) stated that internet users in Saudi Arabia at the end of 2013 approximately 16.5 million internet users, representing 
$55.1 \%$ of the country's total population. Alebaikan and Troudi (2010) noted that it is estimated that internet use will continue growing rapidly in Saudi Arabia, which raises an issue of providing new learning strategies that include use of technology.

Table 2: Usage of KM techniques and technologies within the KSA public sector organisations

\begin{tabular}{|l|c|c|c|c|c|c|}
\hline \multicolumn{1}{|c|}{ KM techniques and technologies } & $\begin{array}{c}\text { Overall } \\
\text { usage }\end{array}$ & $\begin{array}{c}\text { Ran } \\
\mathrm{k}\end{array}$ & Directors & Managers & $\mathrm{t}_{\text {cal }}$ & $\begin{array}{c}\text { Significant } \\
\text { value }(\rho)\end{array}$ \\
\hline Brainstorming & 2.28 & 17 & 2.31 & 2.23 & 0.455 & 0.650 \\
\hline Bulletin Boards & 2.67 & 9 & 2.73 & 2.58 & 0.884 & 0.379 \\
\hline Coaching and Mentoring & 2.62 & 10 & 2.58 & 2.67 & -0.611 & 0.542 \\
\hline Communities of Practice & 2.36 & 14 & 2.34 & 2.37 & -0.178 & 0.859 \\
\hline Cross-Functional Collaboration & 2.76 & 7 & 2.73 & 2.79 & -0.337 & 0.737 \\
\hline Face-to-Face Meetings & 2.86 & 3 & 2.84 & 2.88 & -0.231 & 0.818 \\
\hline Formal Education and Training & 2.81 & 5 & 2.80 & 2.84 & -0.240 & 0.811 \\
\hline Formal on-the-job Training & 2.71 & 8 & 2.78 & 2.60 & 1.031 & 0.305 \\
\hline Help Desks & 2.33 & 16 & 2.27 & 2.42 & -0.918 & 0.361 \\
\hline Informal Networks within the Department & 2.01 & 24 & 1.92 & 2.14 & -1.236 & 0.219 \\
\hline Interaction with Client/Supplier/Customer & 2.57 & 11 & 2.59 & 2.53 & 0.330 & 0.742 \\
\hline Internet & 3.12 & 2 & 2.95 & 3.37 & -2.336 & 0.021 \\
\hline Job Rotation & 2.45 & 12 & 2.48 & 2.40 & 0.516 & 0.607 \\
\hline Knowledge Maps & 2.06 & 23 & 2.03 & 2.09 & -0.351 & 0.726 \\
\hline Project Summaries & 2.24 & 19 & 2.13 & 2.42 & -1.595 & 0.114 \\
\hline Story Telling & 2.25 & 18 & 2.13 & 2.44 & -1.493 & 0.138 \\
\hline Telephone & 3.32 & 1 & 3.22 & 3.47 & -1.513 & 0.133 \\
\hline Video Conferencing & 2.20 & 21 & 2.05 & 2.42 & -1.900 & 0.600 \\
\hline Work Manuals & 2.34 & 15 & 2.27 & 2.44 & -1.005 & 0.317 \\
\hline Viber & 1.71 & 27 & 1.64 & 1.81 & -0.976 & 0.332 \\
\hline WhatsApp & 2.84 & 4 & 2.81 & 2.88 & -0.322 & 0.748 \\
\hline Instagram & 2.21 & 20 & 2.11 & 2.35 & -1.067 & 0.288 \\
\hline Facebook & 2.06 & 22 & 1.91 & 2.28 & -1.830 & 0.070 \\
\hline Twitter & 2.80 & 6 & 2.77 & 2.86 & -0.460 & 0.646 \\
\hline FaceTime & 1.84 & 26 & 1.73 & 2.00 & -1.338 & 0.184 \\
\hline Snapchat & 2.36 & 13 & 2.20 & 2.58 & -1.541 & 0.126 \\
\hline LinkedIn & 1.91 & 25 & 1.81 & 2.05 & -1.231 & 0.221 \\
\hline
\end{tabular}

\subsection{The most widely used KM techniques and technologies}

It is apparent from the Table 2 is that telephone, face-to-face meetings, and formal education and training are top five most widely used KM techniques and technologies. This suggests that conventional techniques for acquiring, developing, sharing and storing knowledge are still used frequently among KSA public sector organisations. For instance, in this study, overall mean value of 3.32, telephone is the most widely used $\mathrm{KM}$ techniques for managing knowledge in 
KSA public sector organisations. The telephone is a simple and familiar tool for communicating and sharing knowledge. In addition, telephone remains important for KM because it could be used to capture and distribute structured knowledge but also enable people to share tacit knowledge. According to Ragab and Arisha (2013) telephones are often considered as a source for knowledge within organisations as through this the exchange of knowledge becomes even more convenient for employees. Furthermore, Dey (2013) noted that the use of a telephone can help to communicate ideas and knowledge with another person at distant place. Therefore, it is evident that the usage of 'telephone' to capture/share knowledge significantly foster externalisation, because the tacit knowledge of experts is articulated and often transferred into written documents by the formulation of the captured knowledge pieces. By the utilisation of expert telephone interviews, recording and reporting the knowledge which was newly developed by the expert in his/her job will be beneficial for creating further new knowledge by other members of the organisation.

In this study, overall mean value of 3.12, internet is the second most widely used KM techniques and technologies within the KSA public sector organisations. In today's knowledge era, the internet and intranet are great ways of allowing individuals to access to wide variety of information and knowledge. Both channels allows employees to acquaint themselves with different areas of knowledge and, by using newsgroups and interaction tools, to access this knowledge first hand without excessive filtering or bias (Kluge, et al., 2001). For instance, one of the respondents noted that:

"Most often we use internet to capture knowledge related to process or public sector management issues from research institutes or from famous business schools. One of the 
key advantages of using internet is the speed of capturing and utilisation of information and knowledge in our day-to-day business".

The above statement clearly suggests that the internet is widely used with in KSA public sector organisations to capture external knowledge. The availability of new technologies, particularly the internet, has been instrumental in catalysing the KM movement. The internet is a great way of allowing individuals to access a wide variety of new knowledge quickly and allows employees to capture themselves with different knowledge by using comprehensive knowledge base, newsgroups and interactive tools, and of immediate value to the employees. Teo and Choo (2001) suggested that using the internet can have a positive impact on competitive intelligence information. Furthermore, they suggested that the quality of competitive intelligence drives organisation performance. Strategies that integrate the internet and traditional competitive advantages are very effective (Porter, 1996). Thus, the strategic use of the internet leads to competitive advantage, because production and procurement can be more effective.

With an overall mean value of 2.86, 'Face-to-Face Meetings' is the third most widely used KM techniques and technologies in the KSA public sector organisations, supporting the notion that social interaction is a pre-requisite for successful KM (Davenport and Prusak, 1998). According to Nonaka and Takeuchi (1995), personal contact enhances the tacit-to-tacit knowledge exchange. Koskinen et al. (2003) view face-to-face interaction as the richest medium to transfer knowledge, as it allows immediate feedback so that understanding can be checked and interpretation corrected. 'Face-to-Face Meetings' happens when individuals physically close to each other engage in a mutual exchange of verbal information. Like other communication mechanisms, it allows the exchange of employees' knowledge throughout the organisation. 
However, exchanging knowledge by means of 'Face-to-Face Meetings' is expected to be more effective compared to other means of knowledge sharing. Interactive networks based on the internet or phone system, for example, are not characterised by employees' physical proximity. Durst and Edvardsson (2012) note that 'Face-to-Face Meetings' is considered as a tool that would contribute in KM within organisation. Al Saifi et al (2016) noted that face-to-face meeting facilitate knowledge sharing in diverse ways including how to use of multiple communication styles, brainstorming and problem-solving, training, consultations and employee rotation. In conclusion, 'face-to-face meetings' based on employees' physical contact and dialogue are likely to result in the diffusion of tacit knowledge throughout the organisation. Therefore, employees enjoy a substantial competitive advantage, in the form of higher productivity, compared to workplaces where this means of knowledge sharing is absent.

In this study, 'WhatsApp' (with a mean value of 2.84) is the fourth most widely used KM techniques and technologies. WhatsApp is considered as a source for sharing knowledge within social media and it is an instant messaging application for smartphones. It allows users to exchange images, videos, and audio or written messages using their Internet connection. Therefore, it is positioned itself as a superior alternative to SMS messaging, which can be very expensive when used in foreign countries due to roaming charges. Wankel (2016) noted that WhatsApp has been widely adopted globally now and has been appreciated within organisations as well through which the knowledge has been efficiently shared internally within the organisation. Furthermore, in the KSA public sector organisations especially younger generation staff preferred to use WhatsApp to capture and share the critical knowledge. However, in the KSA recently WhatsApp has been partially blocked and put restrictions for voice calls. 
Formal Education and Training (with a mean value of 2.81) is the fifth most widely used KM techniques and technologies in this study. The creation of knowledge is essential for the survival of any organisation. Hislop (2013) says that the ability to create knowledge and generate a competitive advantage is now essential for any organisation that wishes to remain sustainable within its marketplace. Knowledge creation is an activity that occurs throughout daily activities, at work or in social setting. Knowledge creation occurs in many dynamic forms, which could be through humanistic means such as formal training and education or talking with people who share similar interests. The creation and development of knowledge is an important and intrinsic feature of KM (Dul, et al., 2011). Vacik et al., (2013) noted that formal education and training programmes creates and spreads the new information/knowledge require for organisations. Wilson (2014) stressed that continuous professional development mainly training and education is thought to be vital to expert and knowledge workers. In summary, formal education and training helps to create new knowledge. Technology can facilitate knowledge creation but cannot replace people. Organisations leverage on their ability to create knowledge, innovate, and generate value with new knowledge. This is knowledge that leads to new and innovative products; knowledge that improves internal processes and operations; or knowledge to improve the strategic decision-making capabilities and direction of the organisation.

\subsection{The least used KM techniques and technologies}

In this study, Viber (with a mean value of 1.71), FaceTime (with a mean value of 1.84) and LinkdIn (1.91), are least used KM techniques and technologies in the KSA public sector organisations. Barhoumi (2015) noted that Viber is one of the cheap and effective sources through which the knowledge sharing could happen, but still there are various factors that have been limiting its application like its declining quality and increasing competitive applications 
within market. FaceTime has been used within organisations for voice calls, conducting meetings and teleconferencing but the application is restricted to limited devices and operating systems which would limit its adoption (Wankel, 2016). Furthermore, the low usage of Viber and FaceTime could be due to the Saudi communications commission withheld some of the Viber and FaceTime services and application and lack of awareness of Viber and FaceTime usage and benefits within the KSA.

The Internet makes it possible for individuals to connect, collaborate and share knowledge, information, document, photo, video, etc. continuously with anyone in the world. Furthermore, people are able to make use of social media tools such as LinkdIn in order to increase range and richness of their networks, gather information/knowledge and nowadays, increasingly organisations are finding ways of integrating social media into their business processes (Gaal et al, 2014).Social networks has been contributing to the development and strengthening of organisations by means of collaborative work between people. Hence it helps to extract the tacit knowledge from external sources. Surowiecki (2005) defined that social media is to make use of the "wisdom of the crowd". Group of people are better at problem solving, fostering decision making than the individuals alone. New ways of inspiring and exploiting knowledge sharing are forcing organisations to expand their knowledge sharing technologies and practices (Mentzaset al., 2007). However, the usage of social network technologies such as LinkdIn is used less for managing knowledge in the KSA public sector organisations.

Informal networks within the department (with a mean value of 2.01) is the another least used KM techniques and technologies in this study. Knowledge which by nature is tacit is stored in the minds of individuals (Haldin-Herrgard, 2000). The need for knowledge to resolve complex 
problem situations requires organisational members to collaborate and share knowledge within and across organisational boundaries. Lundvall (2010) indicated that informal networks of employees are efficient channels to share information and technical know-how. Jenab and Sarfaraz (2012) also highlighted the informal networks as a technique that is adopted by the organisations, through which knowledge is managed effectively within organisations. However, organisations provide a formal structure for collaborative knowledge sharing. Cross and Parker (2004) noted that formal structures and prescribed communication channels fail to develop effective knowledge collaboration among employees. Therefore, the KSA public sector organisations decision makers need to be aware of the strengths of the informal networks mechanism to capture and share internal and external sources of knowledge that can be utilised to resolve complex problems.

In this study, knowledge maps (with a mean value of 2.06) are another least used KM techniques and technologies in the KSA public sector organisations. Davenport and Prusak (1998) note that developing a knowledge map involves locating important knowledge within the organisation and then publishing some sort of list or picture that shows where to find it. One of the main purposes of knowledge maps is to locate important knowledge in an organisation and show users where to find it (Kim, et al., 2003). Effective knowledge maps should point not only to people but to documents and databases as well. Knowledge maps should also locate actionable information, identify domain experts, and facilitate organisation-wide learning (Eppler, 2008). They should also trace the acquisition and loss of knowledge, as well as map knowledge flows throughout the organisation (Grey, 1999). 
In summary, the level of usage of knowledge maps is relatively low in the KSA public sector organisations. This could be due to the fact that mapping of knowledge is in its infancy compared to capturing and sharing knowledge. Therefore, there is an urgent need for developing and deploying sector-wide knowledge mapping awareness programmes. Knowledge maps are powerful tools to inventory an organisation's critical knowledge and pinpoint areas that may be at risk. In many cases, the simple act of creating a knowledge map reveals weak links and bottlenecks in the flow of knowledge. By articulating exactly how knowledge moves through the organisation, teams can identify improvement opportunities and make targeted adjustments to ensure that the right knowledge reaches the right people at the right point in the process. Therefore, knowledge maps can quickly connect experts with each other or help novices identify experts promptly. As a consequence, knowledge maps can speed up the knowledge seeking process and facilitate systematic knowledge development since they connect insights with tasks and problems.

\section{Conclusions}

It is not simply enough for knowledge to reside within an organisation as knowledge that is not effectively utilised is essentially a wasted resource, instead knowledge needs to be actively managed. There are several mechanisms that can be used to manage public sector or private sector organisational knowledge. However, the challenge of managing knowledge is a daunting task for any organisation. An organisation's knowledge resources are complex and multifaceted, ranging from tacit components to knowledge that is explicitly represented. Providing access to key tacit and explicit knowledge to decision makers during potential changes seems to be critical for effective decision-making. Recent technological developments have made a significant and positive impact on the ability and desire to manage knowledge. The survey revealed that 
conventional, simple and cost effective KM techniques and technologies such as telephone, internet, face-to-face meetings, WhatsApp, and formal education and training programmes are extensively used. It is surprising to see that WhatsApp is very widely used technology compared to other modern technologies. It is considered as a source for sharing knowledge within social media and it is an instant messaging application for smartphones. It allows users to exchange images, videos, and audio or written messages using their Internet connection. Therefore, it is positioned itself as a superior alternative to SMS messaging, which can be very expensive when used in foreign countries due to roaming charges.

Whereas, modern KM techniques and technologies such as Viber, FaceTime, LinkdIn, Informal networks, and knowledge maps are less used. Social networks has been contributing to the development and strengthening of organisations by means of collaborative work between people. Hence it helps to extract the tacit knowledge from external sources. However, various restrictions pertaining to internet and social media usage by the KSA Government is hindering the implementation of KM practices. Government and public service delivery is taking place in a changed world. A significant level of social, economic and political activity is now happening on the social networks. It offers a nascent but rapidly growing opportunity to overhaul and significantly enhance the process by which Saudi Government understands society and the impact of its policies. Therefore, the KSA government should take a greater leadership role in shaping the information environment and the role of emerging technologies in society that have significant impacts. The level of usage of knowledge maps is relatively low in the KSA public sector organisations. Therefore, there is an urgent need for developing and deploying sector-wide knowledge mapping awareness programmes. Knowledge maps are powerful tools to inventory an organisation's critical knowledge and pinpoint areas that may be at risk. The paper concludes 
that to gain competitive advantage, it is necessary for KSA public sector decision makers to recognise and use a blend of ICT and non-ICT based KM techniques and technologies. It is advisable to use conventional, simple, low cost, and easy to use with minimum training needs KM techniques and technologies. It should note that KM techniques and technologies roles are not mutually exclusive and KSA public sector organisations may adopt any combination of them to tackle their particular issues or support particular motives.

\section{References}

AF Ragab, M., and Arisha, A. (2013) Knowledge management and measurement: a critical review, Journal of Knowledge Management, Vol. 17, No. 6, pp. 873-901.

Al Saifi, S. A., Al Saifi, S. A., Dillon, S., Dillon, S., McQueen, R., and McQueen, R. (2016) The relationship between face to face social networks and knowledge sharing: an exploratory study of manufacturing firms, Journal of Knowledge Management, Vol. 20, No. 2, pp. 308-326.

Alebaikan, R., and Troudi, S. (2010) Blended learning in Saudi Universities: challenges and perspectives, ALT-J: Research in Learning Technology, Vol. 18, No. 1, pp. 49-59.

Al-Kibsi, G. Woetzel, J. Isherwood, T. Khan, J. Mischke, J and Noura, H. (2015) Moving Saudi Arabia's economy beyond oil, Report McKinsey Global Institute (MGI), New York.

ALSarhani, A. A. (2013) Staff trends towards the application of Knowledge Management in Saudi Arabia: A comparative study between Royal Commission for Jubail and Saudi Kayan Petrochemical Company, Doctoral thesis, King Abdul-Aziz University, Jeddah, Saudi Arabia.

ALSarhani, A. A. (2016) Knowledge Management in the public and private sectors organisations - The Road to Achieve Sustainable Competitive Advantage, Al-Rushd Library, Riyadh, Saudi Arabia.

Alsereihy, H.A., Alyoubi, B.A. and El-Emary, I.M. (2012) "Effectiveness of Knowledge Management Strategies on Business Organizations in KSA: Critical Reviewing Study", MiddleEast Journal of Scientific Research, Vol. 12, No. 2, pp. 223-233.

Alshahrani, H. A. (2016) A Brief History of the Internet in Saudi Arabia, TechTrends, Vol. 60, No. 1, pp.19.

Ashok, M., Ashok, M., Narula, R., Narula, R., Martinez-Noya, A., and Martinez-Noya, A. (2016) How do collaboration and investments in knowledge management affect process innovation in services?, Journal of Knowledge Management, Vol. 20, No. 5, pp. 1004-1024.

Bajpai, N. (2010) Business statistics, Pearson Education, Upper Saddle River, NJ, USA.

Barhoumi, C. (2015) The effectiveness of WhatsApp mobile learning activities guided by activity theory on students' knowledge management, Contemporary Educational Technology, Vol. 6, No. 3, pp. 221-238. 
Bhatt, G. D. (2001) Knowledge management in organizations: examining the interaction between technologies, techniques, and people, Journal of Knowledge Management, Vol. 5, No. 1, pp. 6875.

Black, K. (2010) Business statistics: Contemporary decision making, John Wiley and Sons, Jefferson City, MO.

Bolisani, E. and Handzic, M. (2014) Advances in Knowledge Management: Celebrating Twenty Years of Research, Springer publishing, London, UK.

Bourque LB, and Fielder EP (1995) How to Conduct Self-Administered and Mail Surveys, Sage Thousand Oaks, CA.

Boyne, G.A (2002) Public and Private Management: What's the Difference?, Journal of Management Studies, Vol. 39, No. 1, pp. 97-122.

Bryman, A. and Bell, E. (2015) Business research methods, Oxford University Press, Oxford, UK.

Chua, A. Y., and Banerjee, S. (2013) Customer knowledge management via social media: the case of Starbucks, Journal of Knowledge Management, Vol. 17, No. 2, pp. 237-249.

Colby, A., Ehrlich, T., Sullivan, W. M., and Dolle, J. R., (2011) Rethinking Undergraduate Business Education: Liberal Learning for the Profession, The Carnegie Foundation for the Advancement of Teaching, Jossey-Bass, San Francisco, CA.

Cross, R., and Parker, A. (2004) The hidden power of social networks: understanding how work really gets done in organizations, Harvard Business School Press, Boston, MA.

Datar, S. M., Garvin, D. A., and Cullen P. G. (2011) Rethinking the MBA: Business education at crossroads, Journal of Management Development, Vol. 30, No. 5, pp. 451-462.

Davenport, T. H., and Prusak, L. (1998) Working knowledge: How organizations manage what they know, Harvard Business Press, Boston, USA.

Dey, B. L. (2013) A qualitative enquiry into technology acceptance and appropriation: A case study of Bangladeshi farmers' use of mobile telephony, Journal of Customer Behaviour, Vol. 12, No. 2/3, pp. 261-280.

Drucker, P. F. (1995) Managing in a time of great change, Butterworth-Heinemann, Oxford, UK.

Dul, J., Ceylan, C. and Jaspers, F. (2011) Knowledge workers' creativity and the role of the physical work environment, Human Resource Management, Vol. 50, No. 6, pp. 715-734.

Durst, S. and Edvardsson, R. I. (2012) Knowledge management in SMEs: a literature review, Journal of Knowledge Management, Vol. 16, No. 6, pp. 879-903.

Durst, S., and Edvardsson, R. I. (2012) Knowledge management in SMEs: a literature review, Journal of Knowledge Management, Vol. 16, No. 6, pp. 879-903.

Easterby-Smith, M. and Lyles, M. A. (2011) Handbook of organizational learning and knowledge management, John Wiley and Sons, New York, USA.

Eppler, M. (2008) A Process-Based Classification of Knowledge Maps and Application Examples, John Wiley and Sons Ltd, London, UK. 
EY (2017) From volume to value: the transformation of National Oil Companies, Ernst and Young, London, UK.

Fattouh, B. and Sen, A. (2016) Saudi Arabia's Vision 2030, Oil Policy and the Evolution of the Energy Sector, Oxford Energy Comment, Oxford Institute for Energy Studies, UK.

Fellows, R. F. and Liu, A. M. (2015) Research methods for construction, John Wiley and Sons, London, UK.

Gaál Z., Szabó, L. and Obermayer-Kovács, N. (2014) Personal knowledge sharing: Web 2.0 role through the lens of Generations, ECKM 2014 - Conference Proceedings, 15th European Conference on Knowledge Management, Santarem, pp. 362-370.

globalvoices.org, (2016) Angered by Mobile App Censorship, Saudis Ask: 'What's the Point of Having Internet?, [online] Global Voices Advocacy. Available at: https://advox.globalvoices.org/2016/09/07/angered-by-mobile-app-censorship-saudis-ask-whatsthe-point-of-having-internet/ [Accessed 11 Apr 2016].

Grey, D. (1999) Knowledge mapping: A practical overview, Available at: http://www.smithweaversmith.com/knowledg2.htm [Accessed 11 Apr 2016].

Grix, J. (2010) The Foundation of Research, Palgrave Macmillan, London, UK.

Haldin-Herrgard, T., (2000) Difficulties in diffusion of tacit knowledge in organizations, Journal of Intellectual Capital, Vol. 1, No. 4, pp. 357-365.

Hislop, D. (2013) Knowledge management in organizations: A critical introduction, Oxford University Press, Oxford, UK.

Jenab, K., and Sarfaraz, A. R. (2012) A fuzzy graph-based model for selecting knowledge management tools in innovation processes, International Journal of Enterprise Information Systems (IJEIS), Vol. 8, No.1, pp. 1-16.

Kim, T. H., Lee, J. N., Chun, J. U., and Benbasat, I. (2014) Understanding the effect of knowledge management strategies on knowledge management performance: A contingency perspective, Information and management, Vol. 51, No.4, pp. 398-416.

Kinash, S. (2006) Paradigms, methodology and methods, Bond University, Australia

[online], Available at: <http://bond.edu.au/prod_ext/groups/public/@pub-tlsgen/documents/genericwebdocument/bd3_012336.pdf> [Accessed 16 Apr 2017].

Kluge, J., Stein, W. and Licht, T. (2001) The knowledge unplugged, The McKinsey and company global survey on knowledge management, Palgrave, New York, USA.

Koskinen, K. U., and Pihlanto, P. (2008) Why Knowledge Management in Project-Based Companies? In Knowledge Management in Project-Based Companies, Palgrave Macmillan, UK.

Lin, H. and Hwang, Y. (2014) Do feelings matter? The effects of intrinsic benefits on individuals' commitment toward knowledge systems, Computers in Human Behavior, Vol. 30, No. 1, pp. 191-198.

Lundvall, B. A., (2010) National systems of innovation: toward a theory of innovation and interactive learning, Anthem, London, UK. 
Mentzas, G., Kafentzis, K. and Georgolios, P. (2007) Knowledge services on the Semantic Web, Communications of the ACM, Vol. 50, pp. 53-58.

Morello, R. T., Barker, A. L., Watts, J. J., Bohensky, M. A., Forbes, A. B., and Stoelwinder, J. (2016) A telephone support program to reduce costs and hospital admissions for patients at risk of readmissions: lessons from an evaluation of a complex health intervention, Population health management, Vol. 19, No, 3, pp. 187-195.

Nonaka, I. and Takeuchi, H. (1995) The knowledge-creating company: How Japanese's companies create the dynamics of innovation, Oxford University Press, Oxford, UK.

Nunnally, J. C. (1978) Psychometric theory, McGraw Hill, New York, USA.

Park, M., Jang, Y., Lee, H. S., Ahn, C., and Yoon, Y. S. (2013) Application of knowledge management technologies in Korean small and medium-sized construction companies, KSCE Journal of Civil Engineering, Vol. 17, No, 1, pp. 22-32.

Pfeffer, K., Baud, I., Denis, E., Scott, D., and Sydenstricker-Neto, J. (2013) Participatory spatial knowledge management tools: empowerment and upscaling or exclusion? Information, Communication \& Society, Vol. 16, No, 2, pp. 258-285.

Priyono, A. (2016) Cross-Functional Collaboration in Sustainability Contexts: Exploratory Studies in Remanufacturing Companies, Procedia Economics and Finance, Vol. 35, pp. 553562.

Punch, K. F. (2005) Introduction to social research: Quantitative and qualitative approaches, Sage Publications, Los Angeles, USA.

Rugg, G. and Petre, M. (2007) A Gentle Guide to Research Methods, McGraw-Hill, London, UK.

Ruggles, R. (1998) The State of the Notion: knowledge management in practice California Management Review, Vol. 40, No, 3, pp. 80-89.

Salwa, A., (2015) Knowledge Management Strategies in the Public Sector - Case Study, ChinaUSA Business Review, Vol. 14, No. 3, pp. 159-170.

Saunders, M. Lewis, P. and Thornhill, A. (2009) Research Methods for Business Students, Pearson Education Limited, Harlow, UK.

Siong Choy Chong, Kalsom Salleh, Syed Noh Syed Ahmad, Syed Ikhsan Syed Omar Sharifuddin, (2011) KM implementation in a public sector accounting organization: an empirical investigation, Journal of Knowledge Management, Vol. 15, No. 3, pp. 497-512.

Smiths, M. and De Moor, A. (2004) Effective knowledge management in knowledge-intensive organizations.In Proceedings of Fifth European Conference on Organizational Knowledge, Learning, and Capabilities, Innsbruck, Austria.

Sultan, N. (2013) Knowledge management in the age of cloud computing and Web 2.0: Experiencing the power of disruptive innovations, International Journal of Information Management, Vol. 33, No, 1, pp. 160-165.

Surowiecki, J., (2005) The Wisdom of the Crowds, Anchor Books, New York, USA.

Teo, T. S. H. and Choo, W. Y. (2001) Assessing the impact of using the internet for competitive intelligence, Information and Management, Vol. 39, No, 1, pp. 67-83. 
Todericiu, R. and Stanit, A. (2016) Knowledge Management Practices Improvement in Public Sector Administration, Review of General Management, Vol. 24, No. 2. pp. 33-39.

Vacik, H., Torresan, C., Hujala, T., Khadka, C., and Reynolds, K. (2013) The role of knowledge management tools in supporting sustainable forest management, Forest Systems, Vol. 22, No, 3, pp. 442-455.

Wankel, C. (2016) Developing cross-cultural managerial skills through social media, Journal of Organizational Change Management, Vol. 29, No, 1, pp. 116-124.

Weiers, R. M. (2011) Introduction to business statistics, South-Western Cengage Learning, New York, USA. 